\title{
EXPERIMENTAL INVESTIGATION ON THE EFFECT OF FIN PITCH ON THE PERFORMANCE OF PLATE TYPE FINS
}

\author{
Praveen Pandey $^{1}$, Rozeena Praveen ${ }^{2}$, S.N.Mishra ${ }^{3}$ \\ ${ }^{1}$ Associate Professor, Mechanical Engg Deptt, MMMEC Gorakhpur, U.P., India, ppande@gmail.com \\ ${ }^{2}$ M.Tech. Student, Mechanical Engg Deptt, KNIT Sultanpur, U.P, India, rozeena.parveen45@gmail.com \\ ${ }^{3}$ Professor, Mechanical Engg Deptt, KNIT Sultanpur, U.P, India, snmishraknit@gmail.com
}

\begin{abstract}
Heat transfer enhancement devices are widely used in various industrial, transportation, or domestic applications such as thermal power plants, means of transport, heating and air conditioning systems, electronic equipments and space vehicles. In all these applications, improvements in the efficiency of heat exchangers can lead to substantial cost, space and materials savings.

The research work summarized in this paper presents an experimental investigation on the effect of fin pitch on the fin performance using plate type fins. The experiments were carried out in the laboratory using a test rig having provisions for attaching plate type fins to a flat base plate. The experiments were conducted for different fin pitch settings. Three plate type fins were used in this study. Three fin pitch settings $1 \mathrm{~cm}, 2 \mathrm{~cm}, 3 \mathrm{~cm}$ were employed under free and forced heat transfer conditions. The heat transfer area was kept the same. The fin performance parameters heat transfer coefficient, base temperature and temperature profile along the length of the fin were studied and compared for different cases. Experimental results show that the effect of fin pitch on fin performance is significant. The effect is more pronounced at higher air flow velocities over the fin surface. The maximum increase in convection heat transfer coefficient value obtained is about 20 percent. The increase in heat transfer coefficient value is also manifested by a corresponding decrease in the fin base temperature.
\end{abstract}

Key word: Extended surface heat transfer, plate type fin, fin pitch

\section{INTRODUCTION}

Extended surface heat transfer plays a very important role in heat exchangers involving a gas as one of the fluids. A heat exchanger is a device which is used to transfer thermal energy between two or more fluid, between a solid surface and a fluid, or between solid particulates and a fluid, at different temperatures and in thermal contact. Not only are heat exchangers often used in the process, power, petroleum, airconditioning, refrigeration, cryogenic, heat recovery, alternative fuel, and manufacturing industries, they also serve as key components of many industrial products available in the market. The heat exchangers can be classified in several ways such as, according to the transfer process, number of fluids and heat transfer mechanism.

Heat exchangers, on the basis of constructional details, can be classified into tubular, plate-type, extended surface and regenerative type heat exchangers. The tubular and plate-type exchangers are the primarily used surface heat exchangers with effectiveness below $60 \%$ in most of the cases.

One of the most common methods to increase the heat transfer is by providing extended surface (fins) with an appropriate fin density (fin frequency, fins $/ \mathrm{m}$ ) as per the requirement. This addition of fins can increase the surface area by 5 to 12 times the primary surface area. These types of exchangers are termed as extended surface heat exchangers. Plate-fin and tube-fin heat exchangers are the two most common types of extended surface heat exchangers.

Plate type extended surface heat exchangers have corrugated fins mostly of triangular or rectangular cross-sections sandwiched between the parallel plates. These are widely used in automobile, aerospace, cryogenic and chemical industries, electric power plants, propulsive power plants, systems with thermodynamic cycles i.e. heat pump, refrigeration etc. and in electronic, gas-liquefaction, air-conditioning, waste heat recovery systems etc. They are characterized by high effectiveness, compactness (high surface area density), low weight and moderate cost. The next category is Tube-Fin Heat Exchangers; these heat exchangers may further be classified as (a) conventional and (b) specialized tube-fin exchangers. Tube-fin exchangers are employed when one fluid stream is at a high pressure and/or has a significantly higher heat transfer coefficient than that of the other fluid stream. In a conventional tube-fin heat exchanger, the transfer of heat takes place by conduction through the tube surface.

Bergles et al [1] identified about 14 enhancement techniques used for the heat exchangers. These enhancement techniques 
can be classified into active and passive techniques. Passive techniques do not require any type of external power for the heat transfer augmentation, whereas, the active techniques need some power externally, such as electric or acoustic fields and surface vibration.

A variety of enhanced surface studies have been previously performed that have evaluated heat transfer and flow distribution of enhanced heat transfer surfaces. Webb [2] presents a performance evaluation for enhanced surfaces that relates heat transfer and surface area. $\mathrm{Li}$ and Chen [3] used infrared thermography to investigate the performance of platefin surfaces under confined impinging jet conditions. Sahin and Demir [4] discuss heat transfer rates from fins and how they can be improved by employing slots or porosity.

\section{EXPERIMENTAL SETUP AND PROCEDURE}

Figure 1 shows the schematic diagram of the experimental setup. It consist of a vertical rectangular duct supported by a bench mounted stand .A test section which consist of a base plate in the duct, on which plate type fin are installed. The base plate is secured by a quick release catch on each side. An electric heating element is fitted at the back side of the base plate. With thermostatic protection of overheating, the temperature at the base is monitored by a thermocouple sensor with connecting lead. A fan is situated at the top of the duct provides the air stream in the duct with variable speed. Air velocity in the duct, whether natural or forced, is indicated on a portable anemometer. The anemometer probe is inserted through the wall of the duct. A thermocouple probe permits measurement of air temperature, together with surface temperature of pins and fins. These temperatures are determined by inserting the probe through access holes in the duct wall. An independent bench mounted-console contains temperature measurement, power control, and fan speed control circuit with appropriate instrumentation. Temperature measurement, to a resolution of $0.1^{\circ} \mathrm{C}$, is affected using thermocouple sensor with direct digital read- out in ${ }^{\circ} \mathrm{C}$. An electric console incorporates a solid state power regulator with a digital read-out to control and indicate power supply to exchanger on test. The exchanger is connected to the console via the supply lead. Power is supplied to the equipment via a supply lead connected to the rear of the electric console. The power control circuit provides a continuously variable, electrical output of $0-100 \mathrm{~W}$ with a direct read-out in Watts.

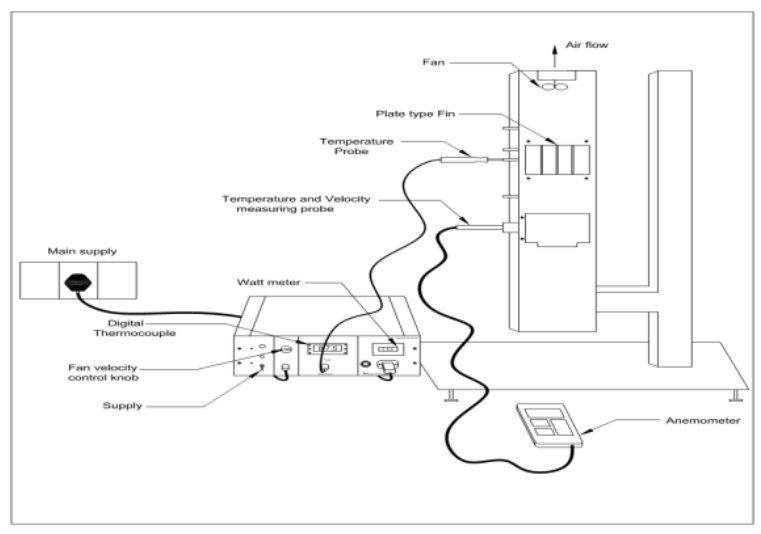

Fig.1 Schematic Diagram for the Experimental Setup

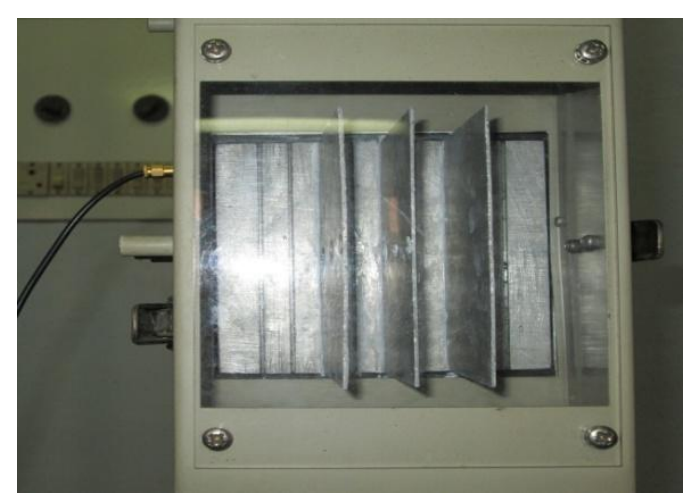

Fig.2 Photograph of the test section

The base plate in the test section is a smooth Aluminum plate of size $100 \mathrm{~mm}$ length and $110 \mathrm{~mm}$ width. The base plate is made slotted type for fixing fins into slots. The plate is divided in nine equidistant slots. The distance between two adjacent slots is kept $10 \mathrm{~mm}$. Plate type fins of size $100 \mathrm{~mm}$ length, $68 \mathrm{~mm}$ width and $1 \mathrm{~mm}$ thick are mounted on the base plate. The whole experiment was carried out on this base plate by changing the fin pitch and fin arrangement. This experimental set-up is basically built up for the performance of fin by changing the pitch distance.

\section{Fin Analysis Methodology}

The rate of heat transfer from the fin

$$
Q_{o}=[p h K A]^{\frac{1}{2}}\left[\frac{\frac{h}{m K}+\tanh (m l)}{1+\frac{h}{m K} \tanh (m l)}\right]\left(T_{s}-T_{\infty}\right)
$$

The energy balance for experimental set-up is $P_{\text {input }}=q_{u}+n \times Q_{o}$, where $P_{\text {input }}=$ Power input to the base
plate. 
$P_{\text {input }}=h\left[A_{u}\left(T_{s}-T_{\infty}\right)\right]+n \sqrt{p h K A}\left[\frac{\frac{h}{m K}+\tanh (m l)}{1+\frac{h}{m K} \tanh (m l)}\right]\left(T_{s}-\right.$
$T \infty$

where $q_{u}$ is the heat lost by uncovered area of base plate, $Q_{o}$ is heat lost by one fin, $n$ is the number of fins used, $A_{u}$ is the uncovered area of base plate. The above equation is used for calculating the heat transfer coefficient in the experimental investigation. The pitch distance between two fins is fixed at $1 \mathrm{~cm}, 2 \mathrm{~cm}$ and $3 \mathrm{~cm}$. Three plain plate type fins were used. The power input was set at $35 \mathrm{~W}$.

\section{RESULT AND DISCUSSIONS}

The experimental results on plate type fins are presented in this section. The experiments were carried out by varying the fin pitch and blower fan speed. Figures 3, 4 and 5 show the variations in temperature with distance from base plate at different fin pitches. Figure 3 shows the results when the fin pitch was kept $1 \mathrm{~cm}$. The experimental results at four settings of blower fan speed are plotted in the Figure 3. It can be seen from the figure that when the fan is switched off (fan velocity zero), which corresponds to the case of free convection, the temperature at the fin base and at different locations is highest. After switching on the blower fan, i.e. under forced convection conditions the temperature of the fin reduces. The experiments were performed for three different settings of fan speed under forced convection. From the Figure 3, it is observed that as the fan velocity increases the fin temperatures at different locations reduced progressively as can been seen from Figures 4 and 5 show results at fin pitch $2 \mathrm{~cm}$ and $3 \mathrm{~cm}$ at the blower fan velocity settings similar to $1 \mathrm{~cm}$ fin pitch case. It is obvious from the Figures 4 and 5 that a similar trend of temperature variations is observed. However, the absolute values of temperatures recorded are different. It is observed that when the blower fan velocity is zero, the temperature recorded for the different fin pitch settings are nearly the same. No perceptible change in the fin base temperature or temperature at different locations along the length of the fin is observed. When the blower fan speed increases the temperature of the fin is observed to be less when the fin pitch distance is increased. The reduction in the temperature with the increase in fin pitch is more pronounced at higher values of blower fan speeds.

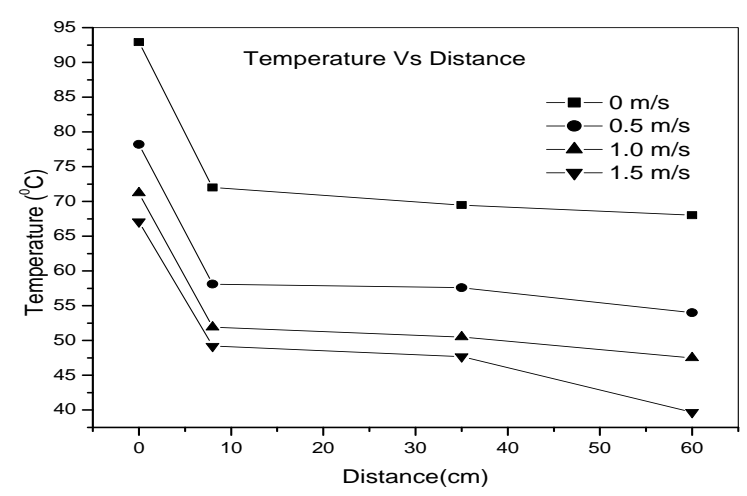

Fig3 Variation of temperature with distance from the base plate at pitch $1 \mathrm{~cm}$

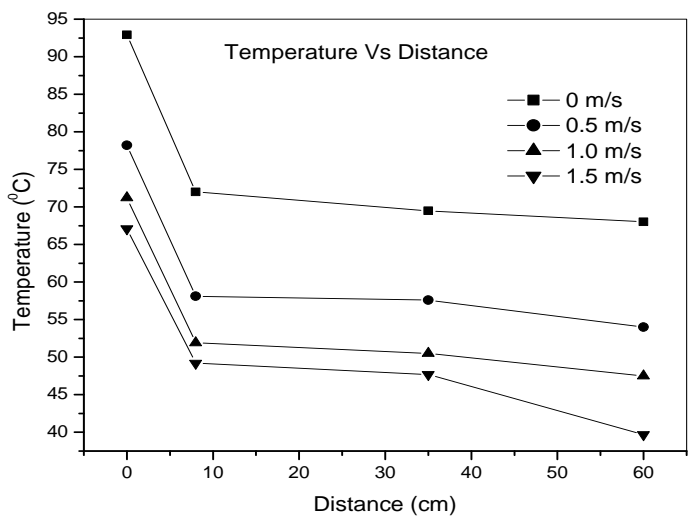

Fig4 Variation of temperature with distance from the base plate at pitch $2 \mathrm{~cm}$

Figures 6, 7 and 8 show the variations in heat transfer coefficient with fan velocity at different fin pitches. Figure 6 shows the results when the fin pitch was kept $1 \mathrm{~cm}$. The experimental findings at four different settings of blower fan speed are depicted in Figure 6. It can be seen from the figure that when the fan is switched off (fan velocity zero), is the case of free convection and the value of convection heat transfer coefficient is at the lowest. After switching on the blower fan, i.e, under forced convection conditions, the heat transfer coefficient at the fin surface increases. 


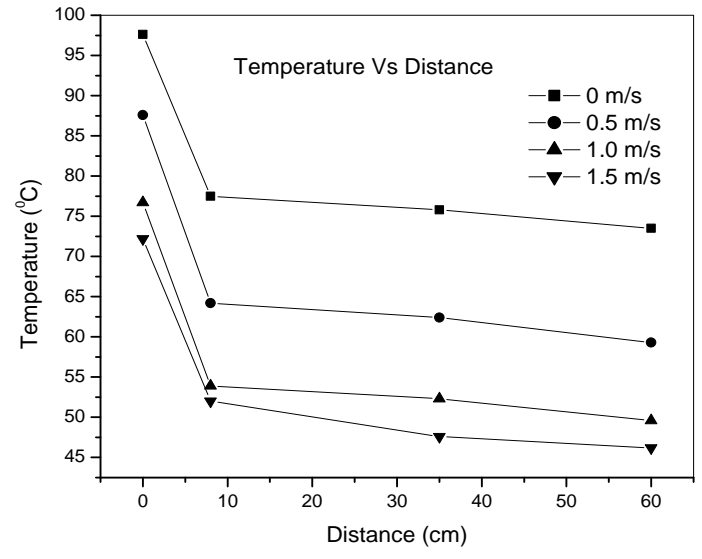

Fig5 Variation of temperature with distance from the base plate at pitch $3 \mathrm{~cm}$

The experiments were performed for three different settings of fan speed under forced convection. From the Figure 6 it can be seen that as the fan velocity increases the heat transfer coefficient also increases. Figures 7 and 8 show that results at fin pitch $2 \mathrm{~cm}$ and $3 \mathrm{~cm}$ at the blower fan velocity settings similar to $1 \mathrm{~cm}$ fin pitch case. Figures 7 and 8 shows that the variations of heat transfer coefficient follow a trend similar to the case of $1 \mathrm{~cm}$ fin pitch case. However, the values of heat transfer coefficient observed are different when the fin pitch setting is changed. It can be seen from Figures 7 and 8 that as the blower fan speed increases the heat transfer coefficient recorded for the different fin pitch settings tend to increase. The change in the heat transfer coefficient with change in fin pitch under free convection is negligibly small, but as the blower fan speed is increased the effect of fin pitch on heat transfer coefficient begins to show. It is observed that heat transfer coefficient tend to be higher when the fin pitch is increased. The increase in the heat transfer coefficient with the increase in fin pitch is more prominent when higher blower fan speed is employed.

Figures 9, 10 and 11 show the variations in base temperature with velocity at different fin pitches. Figure 9 shows the results when the fin pitch was kept $1 \mathrm{~cm}$.

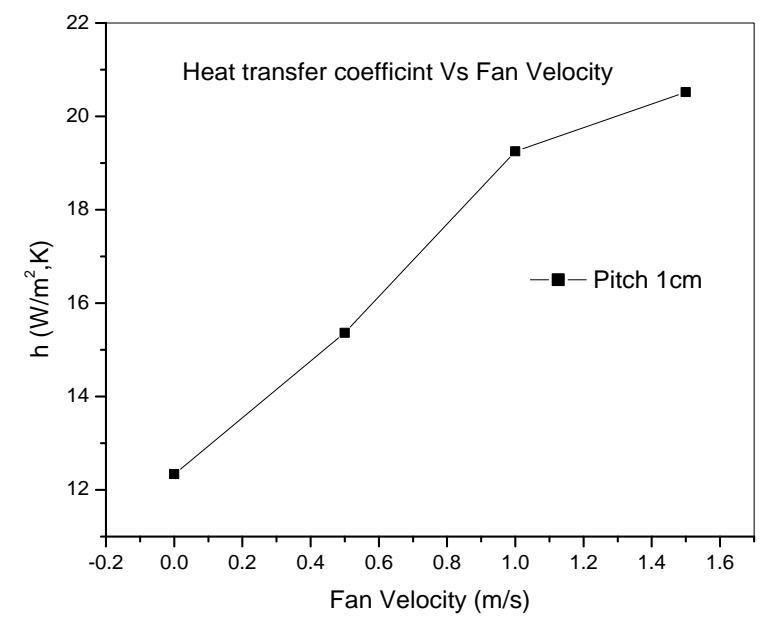

Fig6 Variation of heat transfer coefficient with fan velocity at pitch $1 \mathrm{~cm}$.

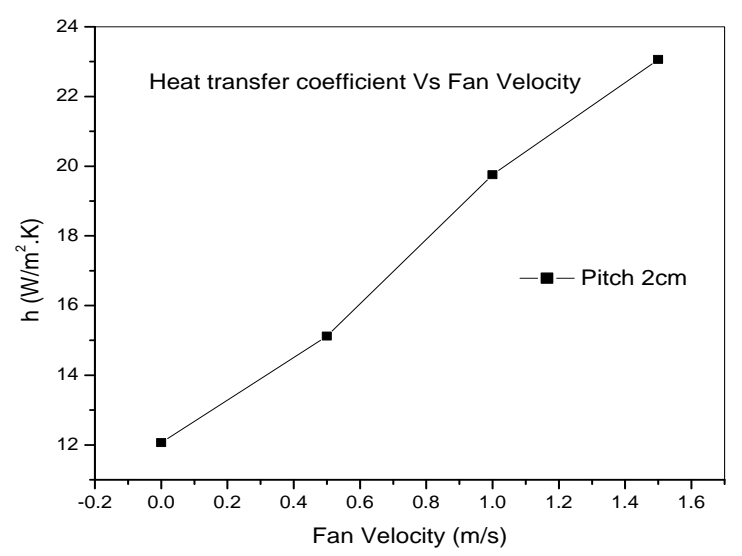

Fig7 Variation of heat transfer coefficient with fan velocity at pitch $2 \mathrm{~cm}$.

The experimental results at four settings of blower fan speed are plotted in the Figure 9. It can be seen from the figure that when the fan is switched off (fan velocity zero), which corresponds to the case of free convection, the temperature at the fin base is the highest. After switching on the blower fan, i.e, under forced convection condition the base temperature of the fin reduces. The experimental results under forced convection conditions, performed for three different settings of fan speed are also shown in the figures. From Figure 9, it is observed that as the fan velocity increases the base temperatures of the fin reduced progressively. 


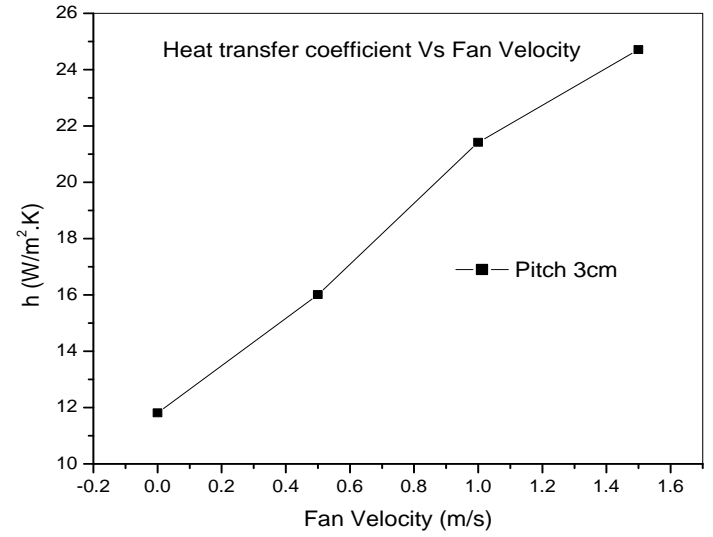

Fig8 Variation of heat transfer coefficient with fan velocity at pitch $3 \mathrm{~cm}$.

Figures 10 and 11 show results at fin pitch $2 \mathrm{~cm}$ and $3 \mathrm{~cm}$ at the blower fan velocity settings similar to $1 \mathrm{~cm}$ fin pitch case. It is obvious from the Figures 10 and 11 that a similar trend of temperature variations is observed, however, the absolute values of temperatures recorded are different. It is observed that when the blower fan velocity increases the temperature recorded for the different fin pitch settings are slightly reduce. No perceptible change in the fin base temperature in case of free convection heat transfer condition is observed. When fin pitch is increased the temperature of the fin is observed to reduce. The reduction in the temperature with the increase in fin pitch is more pronounced when the higher blower fan speed is selected.

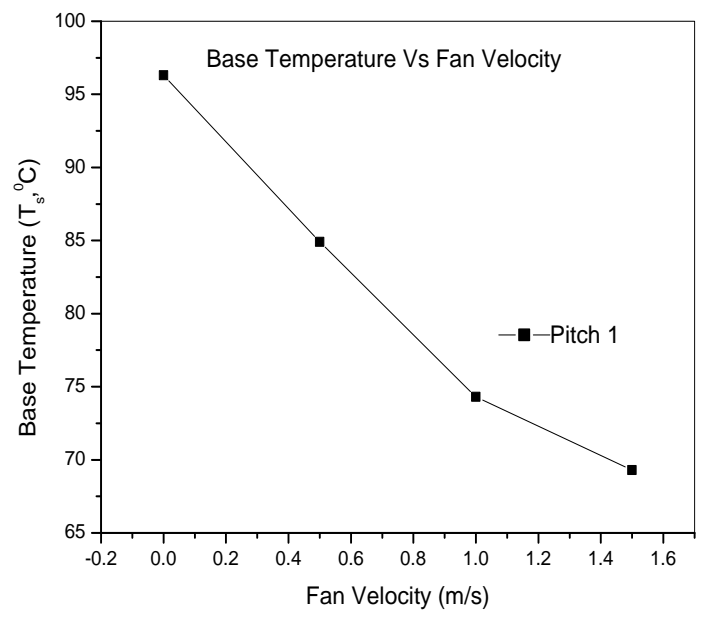

Fig 9 Variation of base temperature with fan velocity at pitch $1 \mathrm{~cm}$

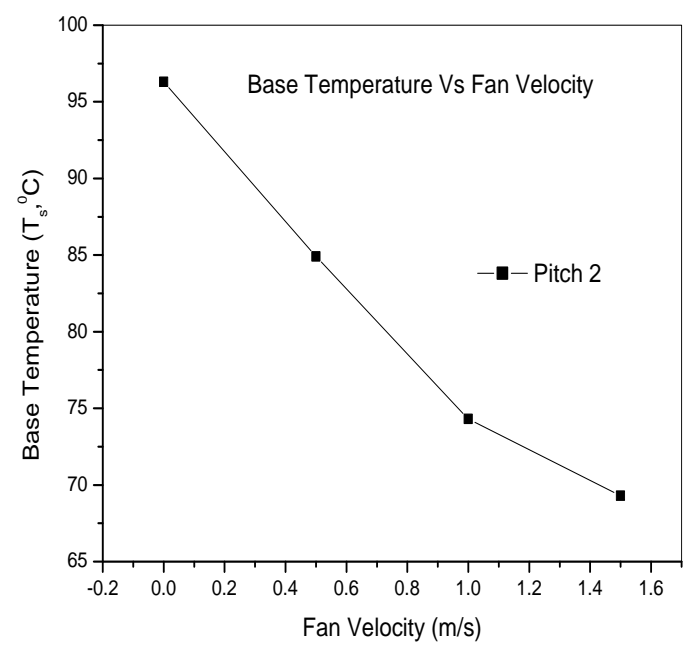

Fig10 Variation of base temperature with fan velocity at pitch $1 \mathrm{~cm}$

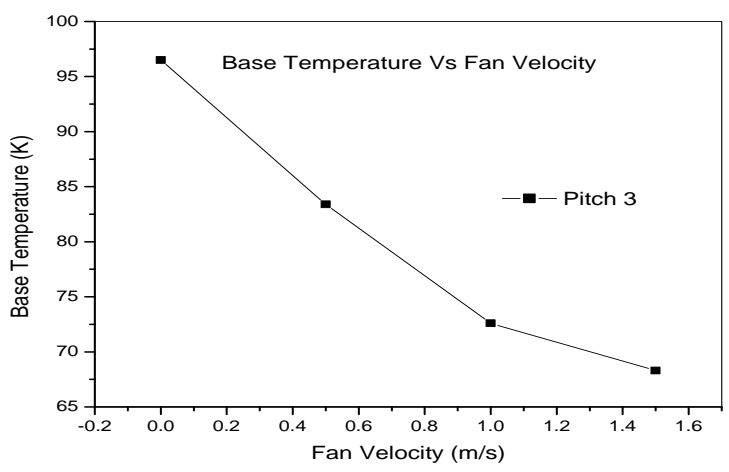

Fig11 Variation of base temperature with fan velocity at pitch $1 \mathrm{~cm}$

A comparative study of the effect of fin pitch on fin performance:

Figure 12 presents a comparative picture of the effect of fin pitch on the base temperature of the fins. The figure reveals that under free convection condition i.e. when the blower fan velocity is zero, the base temperature curve is flat and temperature is almost constant at all the fin pitch values. This effect is corroborateed by the Figure 13 and 14. The two figures show, the variations in convection heat transfer coefficient with fin pitch at different blower fan velocities and convection heat transfer coefficient with fan velocities at different pitchs. These curves show that under free convection condition there is no effect of fin pitch change on the convection heat transfer coefficient. Figure 12 further shows that when the velocity of the blower fan is increased the slope 
of the temperature curve changes. It can be seen from the plot that when the velocity is $0.5 \mathrm{~m} / \mathrm{s}$, there is not much effect on the temperature when the pitch is changed from $1 \mathrm{~cm}$ to $2 \mathrm{~cm}$. However, at pitch setting $3 \mathrm{~cm}$ we see a noticeable drop in the fin base temperature. Figures 13 and 14 show the similar effect of change in fin pitch on the convection heat transfer coefficient. At $0.5 \mathrm{~m} / \mathrm{s}$ velocity, the fin pitch $1 \mathrm{~cm}$ and $2 \mathrm{~cm}$ have nearly the same convection heat transfer coefficient, but at $3 \mathrm{~cm}$ pitch we see a noteworthy increase in the convection heat transfer coefficient. It can be very clearly seen from the Figure 12 that when the blower fan velocity is increased further to $1 \mathrm{~m} / \mathrm{s}$ and $1.5 \mathrm{~m} / \mathrm{s}$, with the increase in fin pitch there is a conspicuous drop in the fin base temperature. Figures 13 and 14 show the similar effect of change in fin pitch on convection heat transfer coefficient.

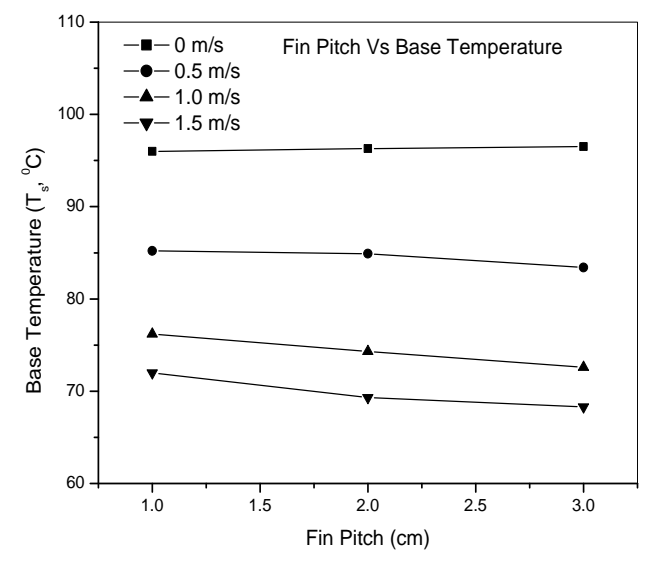

Fig12 Effect of fin pitch and base temperature

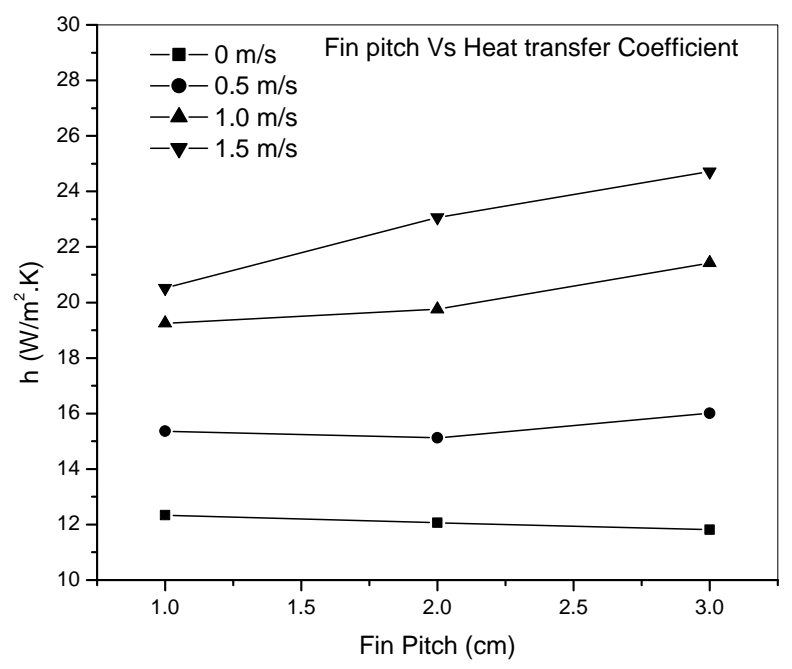

Fig. 13 Effect of fin pitch and heat transfer coefficient.

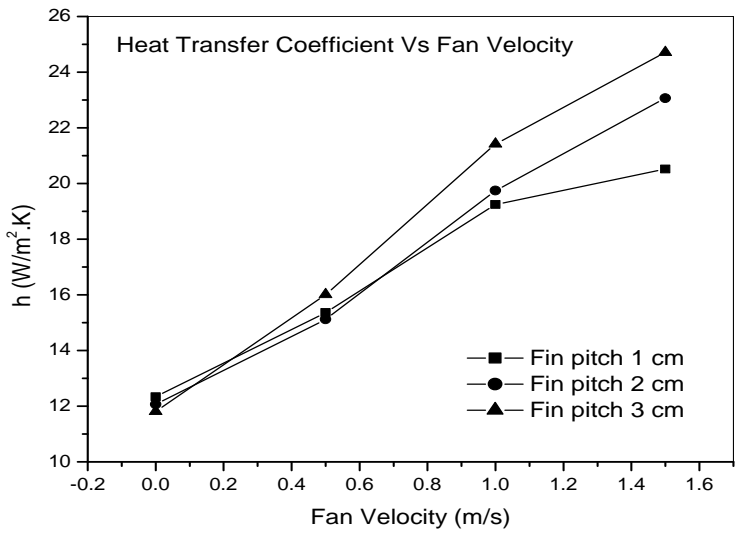

Fig. 14 Effect of fan velocity and heat transfer coefficient

Figures 13 and 14 show when the blower fan velocity is set at higher values of $1 \mathrm{~m} / \mathrm{s}$ and $1.5 \mathrm{~m} / \mathrm{s}$, a noticeable increase in the convection heat transfer coefficient is observed. Thus, it emerges from the above experimental observations that the fin pitch has a significant effect on the fin performance. The effect is not significant under free convection condition, but as the condition changes from free vonvection to forced convection heat transfer, the effect of fin pitch on the fin performance begins to show. At lower velocities, the effect is moderate but at higher velocity settings the effect is considerable. At higher values of the fin pitch, an improved fin performance results.

\section{CONCLUSIONS}

The experiments were carried out for different fin pitch settings under different conditions of free and forced convection heat transfer conditions. The experiments were performed for four flow conditions, one free and three forced heat transfer conditions. The flow was laminar in all the experiments.

- In free convection heat transfer condition, the effect of change in fin pitch on fin performance is not significant. There was no noticeable change in the fin base temperature and convection heat transfer coefficient with the change in fin pitch.

- In forced convection condition, the effect of fin pitch on fin performance is clearly visible. The effect is more pronounced at higher air flow velocities over the fin surface. At $0.5 \mathrm{~m} / \mathrm{s}$ velocity, the convection heat transfer coefficient value increased by about 5 percent when the fin pitch setting is changed from $1 \mathrm{~cm}$ to $3 \mathrm{~cm}$. When the velocity is increased to $1 \mathrm{~m} / \mathrm{s}$ under similar condition, the increase is about 11 percent. Further, when the velocity is increased to $1.5 \mathrm{~m} / \mathrm{s}$, the increase in convection heat transfer coefficient value is about 20 percent, which is a 
significant increase. The increase in heat transfer coefficient value is also manifested by a corresponding decrease in the fin base temperature.

\section{REFERENCES:}

[1] Bergles, A.E., Augmentation of Heat Transfer, Heat Exchanger Design Handbook, Hemisphere Publishing Company, Washington DC, 1983.

[2] Heffington, S. N., 2001, Vibration-induced Droplet Atomization Heat Transfer Cell for Cooling of Microelectronic Components, Proceedings of the IPACK'01, paper 15596.

[3] Yabe, A., 1991, Active Heat Transfer Enhancement by Applying Electric Fields, Proceedings of the Third ASME/JSME Thermal Engineering Conference, Vol. 3, pp.15-23

[4] Pais, M. R., Chow, L.C. and Mahefkey, E.T., 1992, Surface Roughness and its Effects on the Heat Transfer Mechanism in Spray Cooling, Journal of Heat Transfer, Vol. 114, pp. 211-219

[5] Incropera, F., DeWitt, D. (2002): Introduction to Heat Transfer, 4th ed., Wiley, NewYork. 